\title{
EFICIÊNCIA AGRONÔMICA DE SUPERFOSFATO TRIPLO E FOSFATO NATURAL DE ARAD EM CULTIVOS SUCESSIVOS DE SOJA E MILHO
}

\author{
Agronomic efficiency of triple superphosphate and Arad rock phosphate \\ on crop rotation of soybean and corn
}

\author{
Fábio Benedito Ono ${ }^{1}$, Juliano Montagna ${ }^{2}$, José Oscar Novelino ${ }^{3}$, Milson Evaldo Serafim ${ }^{4}$, \\ Daniel Comiran Dallasta ${ }^{5}$, Marcos Vinicios Garbiate ${ }^{6}$
}

\begin{abstract}
RESUMO
Conduziu-se este estudo, com o objetivo de avaliar os efeitos de doses de adubos fosfatados sobre a cultura da soja e do milho, em cultivos sucessivos. O experimento foi realizado em casa de vegetação da UFGD, em vasos contendo amostras de $5,5 \mathrm{dm}^{3} \mathrm{de} u m$ Latossolo Vermelho Distroférrico argiloso, sendo utilizado como fontes de fósforo (P) o superfosfato triplo (SFT) e o fosfato natural de Arad (FNA). O FNA foi utilizado sob duas formas. Em uma, considerou-se o P total (Arad T) e, em outra, apenas a fração de P solúvel em ácido cítrico a 2\% (Arad SA), resultando em três fatores de estudo, cada um em seis níveis de P $(0,56,112,224,336$ e 560), expressos em $\mathrm{mg} \mathrm{dm}^{-3}$. A soja foi semeada em dezembro de $2006 \mathrm{e}$ ao final do ciclo, efetuou-se a colheita, avaliando-se a produtividade de grãos, teores de P na folha e no solo. Após o cultivo da soja, semeou-se o milho, cuja colheita das plantas ocorreu aos 76 dias após a semeadura, sendo avaliados a produção de massa seca da parte aérea e teores de $\mathrm{P}$ na folha. $\mathrm{O}$ índice de eficiência agronômica foi calculado para ambas as culturas. Conclui-se que, para o primeiro cultivo (soja), o SFT apresentou um melhor desempenho no que se refere à produtividade de grãos, quando comparado ao FNA. No cultivo do milho em sucessão a soja, o FNA tendeu a equiparar-se ao SFT nos atributos avaliados.
\end{abstract}

Termos para indexação: Glycine max, Zea mays, adubação fosfatada, fosfato reativo.

\section{ABSTRACT}

The aim of this study was to evaluate the effects of phosphate fertilizer rates on soybean and corn crops, in crop rotation. The experiment was carried out in a greenhouse at the Grande Dourados University, in pots with samples of $5.5 \mathrm{dm}^{3}$ clayey Dystropherric Red Latosol, where the triple superphosphate (TSP) and the Arad rock phosphate (ARP) were used as P source. Two kinds of ARP were used. In one, the total P (Arad T) was considered while in the other, only the P soluble fraction in citric acid at the concentration of $2 \%$ (Arad SA) was considered, resulting in three factors of study, each with six levels of $\mathrm{P}(0,56,112,224,336$, and $560 \mathrm{mg} \mathrm{dm}^{-3}$ ). The soybean was sowed in December 2006 and in the end of the cycle, the crop was harvested and evaluated for grain yield, $\mathrm{P}$ concentration in leaves and in the soil. After the soybean crop, it was turn for the corn sowing, which harvest occurred 76 days after sowing. The shoot dry matter and P concentrations in leaves were evaluated. The Index of Agronomic Efficiency was calculated for both crops. We concluded that the TSP caused a better soybean grain yield, when compared to the ARP. In the corn crop succeeding the soybean crop, the ARP tended to be similar to the TSP values in the attributes evaluated.

Index terms: Glycine max, Zea mays, phosphate fertilizers, reactive rock phosphate.

(Recebido em 9 de abril de 2008 e aprovado em 10 de outubro de 2008)

\section{INTRODUÇÃO}

O cultivo de soja (Glycine max L.) e milho (Zea mays L.) na Região da Grande Dourados, MS é realizado, na sua maior parte, sobre Latossolos oxídicos. Segundo Raij (2004), estes solos estão presentes em grande parte do Brasil e possuem a característica de adsorção pouco reversível de fósforo $(\mathrm{P})$, implicando na necessidade de se adicionar elevadas doses de fertilizantes fosfatados quando se pretende altas produtividades no cultivo destas lavouras. Em razão das peculiaridades dos minerais de argila desses solos em relação ao P, têm sido observadas algumas

\footnotetext{
'Engenheiro Agrônomo, Mestrando em Ciência do Solo - Departamento de Ciência do Solo/DCS - Universidade Federal de Lavras/UFLA - Campus UFLA - Cx. P. 3037 - 37200-000 - Lavras,MG - onofabiob@gmail.com

${ }^{2}$ Engenheiro Agrônomo - Faculdade de Ciências Agrárias/FCA - Universidade Federal da Grande Dourados/UFGD - Rod. Dourados, Itahum Km 12 - Cx. P. 533 - 79804-970 - Dourados,MS - juliano_montagna@hotmail.com

3Engenheiro Agrônomo, Doutor, Professor Adjunto - Faculdade de Ciências Agrárias/FCA - Universidade Federal da Grande Dourados/UFGD - Rod. Dourados, Itahum Km 12 - Cx. P. 533 -79804-970 - Dourados,MS - jnovel@ufgd.edu.br

${ }^{4}$ Engenheiro Agrônomo, Doutorando em Ciência do Solo - Departamento de Ciência do Solo/DCS - Universidade Federal de Lavras/UFLA - Campus UFLA - Cx. P. 3037 - 37200-000 - Lavras,MG - milsonserafim@gmail.com

${ }^{5}$ Graduando em Agronomia - Faculdade de Ciências Agrárias/FCA - Universidade Federal da Grande Dourados/UFGD - Rod. Dourados, Itahum Km 12 Cx. P. 533 - 79804-970 - Dourados,MS - dallasta10@yahoo.com.br

${ }^{6}$ Graduando em Agronomia - Faculdade de Ciências Agrárias/FCA - Universidade Federal da Grande Dourados/UFGD - Rod. Dourados, Itahum Km 12 - Cx. P. 533 - 79804-970 - Dourados,MS - marcos garbiate@yahoo.com.br
} 
dificuldades em se definir níveis ótimos de adubação, quando se visa a elevadas produtividades.

Nas adubações de base (semeadura), o P é geralmente fornecido às plantas na forma de fosfatos solúveis. Contudo, para contornar o problema dos custos destes fosfatos, obtidos por processos convencionais de solubilização de rochas fosfatadas, vem sendo proposto o uso de fontes alternativas de P (Harger et al., 2007). A viabilidade destas fontes está relacionada com a existência de grandes jazidas de fosfato natural, em diversas regiões do país, com baixo custo (Goedert \& Lopes, 1987), associado a seu potencial na apresentação de um efeito residual compensatório, quando comparado com os fosfatos solúveis (Resende et al., 2006). Fertilizantes de menor reatividade, ao disponibilizarem mais lentamente o $\mathrm{P}$, poderiam favorecer a maior eficiência de utilização do nutriente pelas culturas (Novais \& Smyth, 1999).

Os resultados de pesquisas e as indicações técnicas para o uso dos fosfatos naturais reativos, na substituição das fontes solúveis, ainda suscitam dúvidas quanto ao melhor manejo. Porém, existe consenso de que os fosfatos mais solúveis proporcionam maior resposta no ano da aplicação, enquanto os fosfatos naturais têm menor eficiência inicial. Com o tempo, as diferenças de eficiência entre fontes tendem a diminuir (Horowitz \& Meurer, 2003).

É possível que para solos com elevada capacidade de fixação de $\mathrm{P}$, algumas fontes com menor solubilidade em água possam, ao longo do tempo, se tornarem alternativas viáveis sob o ponto de vista agronômico e econômico, em comparação às fontes de elevada solubilidade em água (Braga, 2006).

Nesse contexto, objetivou-se, no presente trabalho, avaliar os efeitos de diferentes doses de $\mathrm{P}$ provenientes de fosfato natural de Arad e do superfosfato triplo sobre o cultivo sucessivo da soja e do milho em Latossolo Vermelho Distroférrico, em casa-de-vegetação.

\section{MATERIAL E MÉTODOS}

O experimento foi realizado em casa-de-vegetação, na Faculdade de Ciências Agrárias da Universidade Federal da Grande Dourados, MS, no período de novembro de 2006 a agosto de 2007, em vasos contendo $5,5 \mathrm{dm}^{3}$ de solo seco ao ar, passado em peneira de $4 \mathrm{~mm}$ de abertura. $\mathrm{O}$ solo utilizado neste estudo, classificado como Latossolo Vermelho Distroférrico, textura argilosa, foi coletado na profundidade de 0 a $20 \mathrm{~cm}$, em uma área sob Brachiaria decumbens Stapf., sem pastejo, pertencente ao Aeroporto Municipal de Dourados, cujas características químicas e físicas iniciais são as seguintes: $\mathrm{pH}$ em água $=5,1 ; \mathrm{P}_{\text {Mehlich } 1}=$
$4 \mathrm{mg} \mathrm{dm}{ }^{-3} ; \mathrm{P}_{\text {resina }}=7 \mathrm{mg} \mathrm{dm}{ }^{-3} ; \mathrm{K}^{+}, \mathrm{Ca}^{2+}, \mathrm{Mg}^{2+}, \mathrm{H}^{+}+\mathrm{Al}^{3+}, \mathrm{SB}$, $\mathrm{T}\left(\mathrm{cmol}_{\mathrm{c}} \mathrm{dm}^{-3}\right)=0,24 ; 2,16 ; 0,70 ; 6,20 ; 3,10 ; 9,30$ respectivamente; $\mathrm{V} \%=33$; $\operatorname{argila}=670 \mathrm{~g} \mathrm{~kg}^{-1} ;$ silte $=160 \mathrm{~g}$ $\mathrm{kg}^{-1}$; areia $=170 \mathrm{~g} \mathrm{~kg}^{-1}$.

$\mathrm{O}$ delineamento experimental utilizado foi em blocos casualizados com quatro repetições e os tratamentos arranjados em um fatorial $3 \times 6$. Foram utilizadas duas fontes de $\mathrm{P}$, sendo o superfosfato triplo ( $44 \%$ de $\mathrm{P}_{2} \mathrm{O}_{5}$ total) e o fosfato natural de Arad (33\% de $\mathrm{P}_{2} \mathrm{O}_{5}$ total e $10 \%$ solúvel em ácido cítrico a $2 \%$ 1:100). A fonte de fosfato natural de Arad (FNA) foi utilizada sob duas formas. Na primeira, considerou-se o P total (Arad T), enquanto que, na segunda forma, apenas a fração de $\mathrm{P}$ solúvel em ácido cítrico a $2 \%$ (Arad SA). Assim, obtiveram-se três fatores de estudo (1Arad T; 2- Arad SA; 3- SFT), cada um com seis níveis de $\mathrm{P}$ $\left(0,56,112,224,336\right.$ e 560), expressos em $\mathrm{mg} \mathrm{dm}^{-3}$, definidos com base no valor do $\mathrm{P}$ remanescente do solo estudado (Alvarez et al., 2000).

Na correção da acidez do solo, utilizou-se calcário “filler", visando a elevar a saturação por bases para $60 \%$ e, após a incubação por um período de 30 dias, o solo de cada vaso foi seco ao ar e acrescido dos tratamentos de $\mathrm{P}$, seguido de agitação para sua homogeneização. Na sequência, efetuou-se a adubação de semeadura com macro e micronutrientes, segundo recomendação para o cultivo em casa-de-vegetação descrita em Novais et al. (1991), exceto para o N, o qual foram fornecidos apenas $25 \%$ do valor recomendado, por ter sido realizada a inoculação das sementes com bactérias do gênero Bradyrhizobium. As amostras de SFT e FNA, utilizadas neste estudo, foram trituradas, passadas através da peneira de $0,84 \mathrm{~mm}$ de abertura e homogeneizadas.

A semeadura da soja ocorreu em 11 de dezembro de 2006, utilizando-se a cultivar M-SOY 5942, de ciclo precoce, sendo o desbaste realizado no $15^{\circ}$ dia após a semeadura, deixando-se duas plantas por vaso. $\mathrm{O}$ teor de água utilizado na irrigação dos vasos foi mantido entre 55 a $65 \%$ do volume total de poros do solo, durante todo o experimento, inclusive no período de repouso (intervalo entre a colheita da soja e a semeadura do milho), com reposições da água evapotranspirada controlada mediante pesagens diárias dos vasos.

A soja foi cultivada até o final do ciclo, cuja colheita ocorreu em 02 de abril de 2007. As características avaliadas foram: produtividade de grãos (PG) e teores de $\mathrm{P}$ na folha. Os grãos depois de colhidos foram acondicionados em sacos de papel e mantidos em estufa com circulação forçada de ar, a $60^{\circ} \mathrm{C}$, até massa constante, a fim de uniformizar o teor de água e, após, determinou-se a PG. 
Para a determinação dos teores de $\mathrm{P}$ na folha de soja, foi coletado no florescimento pleno, estádio R2, o terceiro trifólio, com pecíolo, de cada planta. O material foi seco em estufa de circulação forçada de ar a $60^{\circ} \mathrm{C}$, até massa constante e, em seguida, triturado e homogeneizado. Após digestão nítrico-perclórica das amostras (Malavolta et al., 1997), determinaram-se, nos extratos, os teores de P por colorimetria (Braga \& Defelipo, 1974).

Os restos culturais da soja foram fragmentados em tamanhos variando de 4 a $8 \mathrm{~cm}$ de comprimento e depositados na superfície dos vasos, após a colheita. A partir daí, foram coletadas amostras do solo de cada vaso, utilizando um trado de rosca, para a determinação dos níveis de P pelo método da resina trocadora de íons (Raij et al., 1986).

No dia 17 de maio de 2007, efetuou-se a semeadura do milho híbrido duplo DG-213 Turbo, super precoce. O desbaste foi realizado no $21^{\circ}$ dia após a semeadura, mantendo-se uma planta por vaso. No estádio $\mathrm{V}_{3}$ e $\mathrm{V}_{6}$, aplicou-se em cobertura 25 e $50 \mathrm{mg} \mathrm{dm}^{-3} \mathrm{de} \mathrm{N}$, respectivamente, na forma de uréia. As plantas (parte aérea) foram colhidas aos 76 dias após a semeadura, no início do pendoamento, quando foram avaliadas as seguintes características: produção de massa seca da parte aérea (MSPA) e teores de P na folha.

A MSPA foi determinada após a secagem do material em estufa com circulação forçada de ar na temperatura de $60^{\circ} \mathrm{C}$, até massa constante. As amostras de tecido foliar para determinação do teor de $\mathrm{P}$ foram retiradas da $4^{\mathrm{a}}$ folha a partir do ápice da planta, cuja inserção da bainha com o limbo era visível, utilizando metade da folha, a partir da lígula, eliminando-se a nervura principal e cujos procedimentos analíticos de análise de tecido foram os mesmos utilizados para a cultura da soja.

A eficiência dos fertilizantes fosfatados foi avaliada por meio do índice de eficiência agronômica (IEA), proposto por Barnes \& Kamprath (1975), o qual é calculado por meio da relação percentual entre a produtividade propiciada pelas fontes de $\mathrm{P}$, aplicadas na mesma dose, subtraindo-se de ambas a produtividade do tratamento sem adubação fosfatada, sendo calculada da seguinte forma: $\operatorname{IEA}(\%)=[(Y 2-Y 1) /(Y 3-Y 1)] \times 100$

Em que, $Y 1=$ PG ou MSPA obtida pelo tratamento na dose "zero" de P; $Y 2=\mathrm{PG}$ ou MSPA obtida com a fonte na dose $\mathrm{n}\left(56,112,224,336\right.$ e $560 \mathrm{mg} \mathrm{dm}^{-3}$ de P); e $Y 3=\mathrm{PG}$ ou MSPA obtida pela fonte referência (SFT) na mesma dose n. $\mathrm{O}$ valor $Y 1$ foi obtido pela média de 12 parcelas do tratamento onde se omitiu a aplicação de $\mathrm{P}$.

Os dados coletados foram submetidos à análise de variância e, quando verificada significância dos fatores em estudo, pelo teste $\mathrm{F}$, as médias das fontes foram comparadas pelo teste de Tukey, ao nível de 5\% de probabilidade e, para as variáveis quantitativas, foram ajustadas equações de regressão.

\section{RESULTADOS E DISCUSSÃO}

\section{a) Primeiro cultivo (soja)}

A PG, os teores de P na folha e no solo foram influenciados de forma positiva e significativa $(p<0,01)$ pelas doses, fontes e pela interação entre doses e fontes de $P$.

A fonte de Arad SA foi superior ao Arad T na maioria das doses de P em estudo para a PG (Tabela 1), justamente por ter sido considerado na definição das doses $33 \%$ de $\mathrm{P}_{2} \mathrm{O}_{5}$ para a fonte Arad T e apenas $10 \%$ para a fonte Arad SA, o que equivale aplicar o Arad SA em doses 3,3 vezes maior do que aquelas utilizadas para o Arad T.

Nas adubações com FNA, em geral, tanto nas produções comerciais de grãos como em experimentação agrícola (Korndorfer et al., 1999; Gomes et al., 2005; Santos et al., 2005; Resende et al., 2006), as doses empregadas são calculadas com base na concentração do $\mathrm{P}_{2} \mathrm{O}_{5}$ total do fosfato. Nesse caso, comparando-se o SFT com o Arad T dentro das doses de P (Tabela 1) para a PG, observou-se a superioridade do SFT em todas as suas doses neste estudo, exceto quando o $\mathrm{P}$ não foi aplicado.

Resultados semelhantes foram obtidos por Santos et al. (2005), quando da avaliação com diferentes culturas (soja, milho, feijão, algodão, milheto, braquiária e arroz) em Latossolo Vermelho Amarelo fertilizado com SFT ( $46 \%$ de $\mathrm{P}_{2} \mathrm{O}_{5}$ ) ou FNA $\left(33 \%\right.$ de $\mathrm{P}_{2} \mathrm{O}_{5}$ ) na dose de $150 \mathrm{mg} \mathrm{dm}^{-3} \mathrm{de} \mathrm{P}$, os quais observaram que as culturas responderam significativamente à adubação de $\mathrm{P}$, com superioridade para o SFT na produção de massa seca da parte aérea, com exceção do algodão e do milheto, onde não foram constatadas diferenças entre as fontes. Estes autores argumentam que as menores produções proporcionadas pelo uso do FNA são refletidas pelas solubilizações mais lentas desse fertilizante, não permitindo suprir a demanda das plantas e, consequentemente, promovendo restrição ao seu crescimento e desenvolvimento.

Nas três maiores doses de P $\left(224,336\right.$ e $\left.560 \mathrm{mg} \mathrm{dm}^{-3}\right)$, mesmo na comparação de valores semelhantes de P solúvel, o SFT diferiu significativamente $(\mathrm{p}<0,05)$ do Arad SA (Tabela 1), ficando dessa forma mais evidente a superioridade do uso do SFT em comparação ao FNA na PG. 
Tabela 1 - Valores médios de produtividade de grãos de soja, teores de P na folha e no solo para doses e fontes de P.

\begin{tabular}{|c|c|c|c|c|c|c|}
\hline \multirow[t]{2}{*}{ Fontes } & \multicolumn{6}{|c|}{ Doses de Fósforo $\left(\mathrm{mg} \mathrm{dm}^{-3}\right)$} \\
\hline & 0 & 56 & 112 & 224 & 336 & 560 \\
\hline \multicolumn{7}{|c|}{ 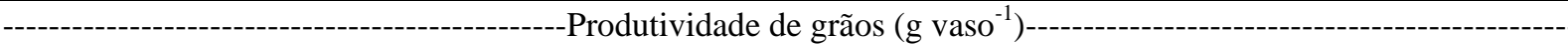 } \\
\hline Arad T & $7,02 \mathrm{a}$ & $16,33 \mathrm{~b}$ & $20,13 \mathrm{~b}$ & $24,66 \mathrm{~b}$ & $25,62 \mathrm{c}$ & $24,57 \mathrm{c}$ \\
\hline Arad SA & $7,22 \mathrm{a}$ & $22,87 \mathrm{a}$ & $26,64 \mathrm{a}$ & $25,80 \mathrm{~b}$ & $32,49 \mathrm{~b}$ & $31,94 \mathrm{~b}$ \\
\hline SFT & $7,06 \mathrm{a}$ & $23,04 \mathrm{a}$ & $30,70 \mathrm{a}$ & $39,71 \mathrm{a}$ & 39,72 a & $43,51 \mathrm{a}$ \\
\hline & & Teores d & folha ( $\mathrm{g} \mathrm{l}$ & & & \\
\hline Arad T & $1,55 \mathrm{a}$ & $2,50 \mathrm{a}$ & $2,58 \mathrm{a}$ & $2,27 \mathrm{~b}$ & $2,49 \mathrm{a}$ & $2,74 \mathrm{~b}$ \\
\hline Arad SA & $1,91 \mathrm{a}$ & $2,65 \mathrm{a}$ & $2,73 \mathrm{a}$ & $3,09 \mathrm{a}$ & $2,68 \mathrm{a}$ & $2,78 \mathrm{~b}$ \\
\hline SFT & $1,85 \mathrm{a}$ & $2,47 \mathrm{a}$ & $2,50 \mathrm{a}$ & $2,77 \mathrm{a}$ & $2,92 \mathrm{a}$ & $3,46 \mathrm{a}$ \\
\hline & & -Teores & solo (ms & & & \\
\hline Arad T & $1,97 \mathrm{a}$ & $10,85 \mathrm{a}$ & $18,47 \mathrm{~b}$ & $48,18 \mathrm{~b}$ & $67,68 \mathrm{~b}$ & $64,75 \mathrm{c}$ \\
\hline Arad SA & $1,49 \mathrm{a}$ & $32,86 \mathrm{a}$ & $57,61 \mathrm{a}$ & $116,21 \mathrm{a}$ & $100,81 \mathrm{a}$ & $160,48 \mathrm{a}$ \\
\hline SFT & $1,35 \mathrm{a}$ & $15,44 \mathrm{a}$ & $30,39 \mathrm{~b}$ & $55,52 \mathrm{~b}$ & $90,28 \mathrm{ab}$ & $119,22 b$ \\
\hline
\end{tabular}

Médias seguidas da mesma letra na coluna não diferem pelo teste de Tukey a 5\% de probabilidade.

Os teores de $\mathrm{P}$ nas folhas, nas quatro menores doses de $\mathrm{P}$ estudadas, foram numericamente maiores com o uso do Arad SA em relação ao SFT, mas tais resultados não diferiram estatisticamente $(\mathrm{p}<0,05)$. Provavelmente, em razão da diferença na velocidade de solubilização entre as fontes, o SFT propiciou uma maior disponibilidade de $\mathrm{P}$ durante a fase vegetativa da cultura que, com isto, apresentou maior crescimento, ficando o $\mathrm{P}$ mais diluído em suas estruturas, o que não deve ter ocorrido para o Arad SA. Já nas duas maiores doses o SFT superou o Arad SA, diferindo significativamente apenas na dose de $560 \mathrm{mg}$ $\mathrm{dm}^{-3}$ de P. Esta inversão deve estar relacionada com o consumo de luxo nestas doses, o que estreita a relação entre o valor absorvido do elemento e o acúmulo de massa seca, comparado àqueles absorvidos nas menores doses.

Quanto aos teores de P no solo a fonte Arad SA foi superior estatisticamente $(\mathrm{p}<0,05)$ ao Arad $\mathrm{T}$, exceção nas doses 0 e $56 \mathrm{mg} \mathrm{dm}^{-3}$ de P (Tabela 1). Já para o SFT o teor foi menor em comparação ao Arad SA em todas as doses, com significância $(\mathrm{p}<0,05)$ nas doses de 112,224 e $560 \mathrm{mg} \mathrm{dm}^{-3}$ de P. Isso pode estar associado à alta solubilidade do SFT, que libera prontamente grande parte do $\mathrm{P}$ aplicado, coincidindo com o período de crescente absorção e acúmulo do elemento pela planta, o que propicia maior incremento de biomassa e maior imobilização do elemento P.

Soma-se a essa imobilização a elevada fixação do P solubilizado nesse tipo de solo (Novais \& Smyth, 1999), que é menos acentuada para o P do FNA, o qual não é solubilizado de forma imediata, permanecendo mais protegido das reações com o solo, minimizando o processo de fixação, mas disponibilizando menos $\mathrm{P}$ para as plantas. Esse balanço é a razão dos maiores teores de $\mathrm{P}$ no solo, para o Arad SA, após o cultivo da soja.

As produtividades máximas de grãos estimadas por meio das equações (Figura 1), em g vaso ${ }^{-1}$, de 25,4 para o Arad T, 31,8 para o Arad SA e 44,1 g para o SFT, foram obtidas com as doses de P, em mg dm ${ }^{-3}$, de 457,2; 479,7 e 684,1 , respectivamente. A dose de 457,2 $\mathrm{mg} \mathrm{dm}^{-3}$ de P que propiciou a produtividade máxima do Arad $\mathrm{T}$, deve corresponder a uma PG de 42,8 $\mathrm{g} \mathrm{vaso}^{-1}$ se fornecida com o SFT. A solubilidade lenta do Arad T, abaixo da demanda pelas plantas, pode ter sido a causa de tais resultados, corroborando com Silva et al. (1999).

Para a PG, o modelo que apresentou o melhor ajuste para as fontes de $\mathrm{P}$ foi o raiz quadrada (Figura 1). A soja respondeu à adubação fosfatada apresentando aumento de PG contundente já na dose de $56 \mathrm{mg} \mathrm{dm}^{-3}$ de $\mathrm{P}$, tendendo a estabilizar na dose de $112 \mathrm{mg} \mathrm{dm}^{-3}$ para o FNA e na dose de $224 \mathrm{mg} \mathrm{dm}^{-3}$ para o SFT.

Nos teores de P na folha de soja os modelos que melhor se ajustaram às fontes foram o raiz quadrada para as duas formas de FNA estudadas e o linear para o SFT (Figura 1). Este comportamento do fosfato natural pode, em parte, ser explicado pela sua solubilidade; isto é, quanto maior a dose, mais próximo de atingir o produto de solubilidade e, portanto, menor a reatividade (Korndorfer et al., 1999).

Houve resposta positiva e linear da aplicação de SFT para os teores de P no solo (Figura 2). Para o Arad T e o Arad SA o melhor modelo ajustado foi o quadrático, cujo comportamento observado para o FNA pode ser entendido a partir do que foi mencionado para os teores de $\mathrm{P}$ na folha (Figura 1). 

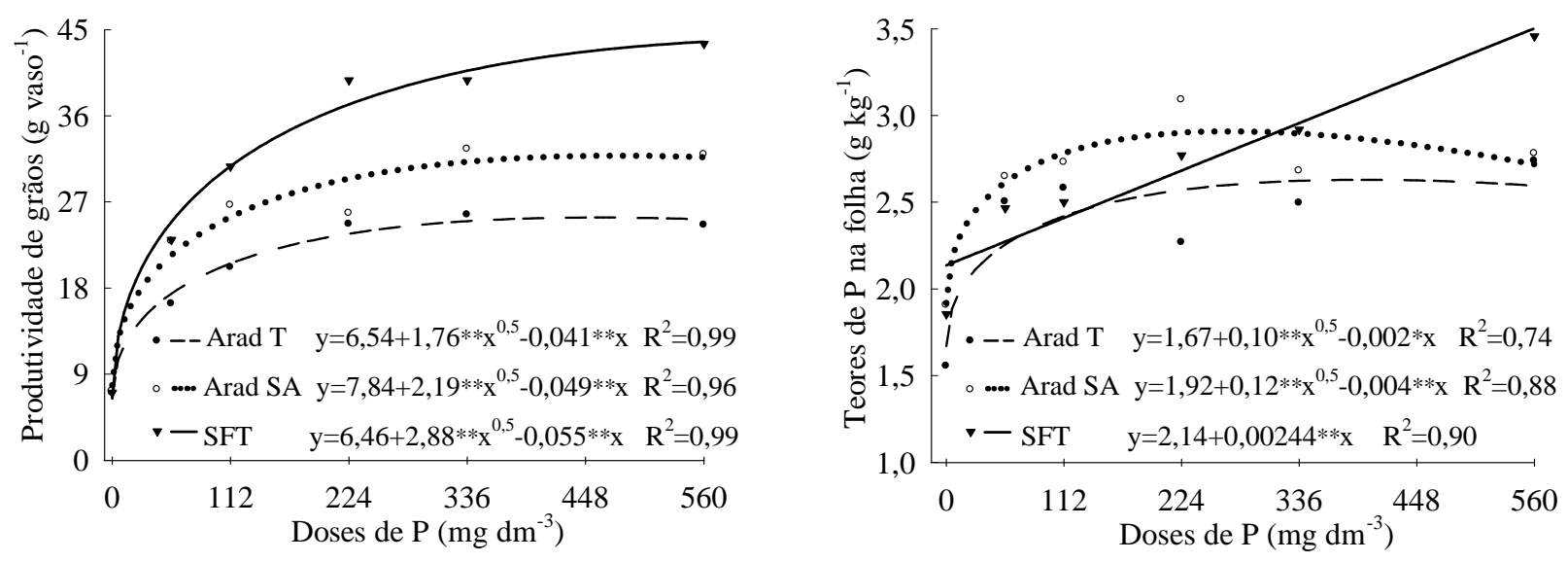

Figura 1 - Produtividade de grãos e teores de P na folha de soja em função das doses de P de três fontes utilizadas. ** e * significativo a 1 e a $5 \%$ de probabilidade pelo teste $t$.

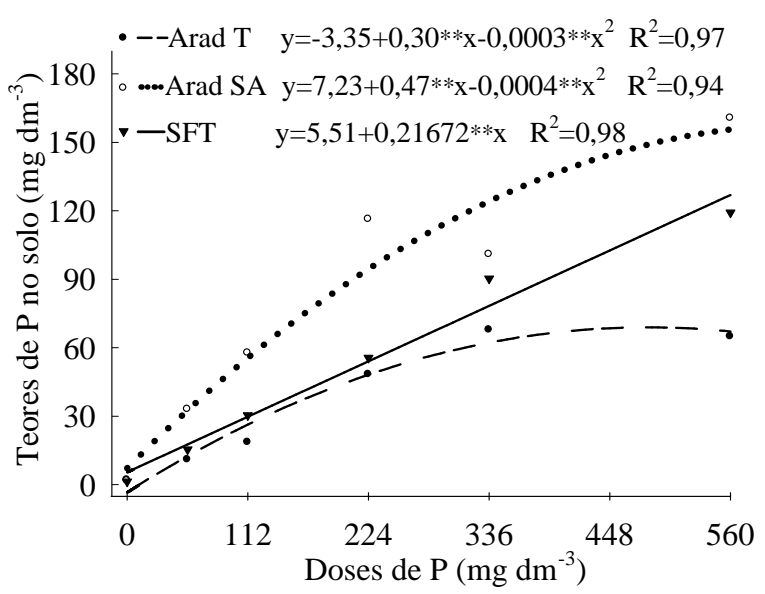

Figura 2 - Teores de P no solo em função das doses de P de três fontes utilizadas. $* *$ significativo a $1 \%$ de probabilidade pelo teste $\mathrm{t}$.

\section{b) Segundo cultivo (milho)}

Os dados médios, com a comparação de médias entre fontes, para a produção de massa seca da parte aérea e teores de P nas folhas do milho, em função de doses de fósforo aplicado, estão apresentados na Tabela 2.

Quanto aos teores de $\mathrm{P}$ na folha de milho não houve diferença significativa $(\mathrm{p}<0,05)$ entre o Arad SA e Arad T (Tabela 2) nas doses estudadas e, no que se refere a MSPA apenas constatou-se diferença significativa na dose de $112 \mathrm{mg} \mathrm{dm}^{-3}$ de P. Isso indica para essas condições de cultivo, considerando o efeito residual de $\mathrm{P}$ para a cultura do milho em sucessão a soja, que não deve haver diferença em adicionar o $\mathrm{P}$ tendo por base o teor de $\mathrm{P}_{2} \mathrm{O}_{5}$ total de $33 \%$ ou o teor solúvel em ácido cítrico a $2 \%$, que é de $10 \%$ de $\mathrm{P}_{2} \mathrm{O}_{5}$ da fonte FNA. Assim, levando-se em conta o efeito residual, a fonte Arad T é economicamente mais viável, pela redução em 3,3 vezes da dose utilizada na condição do Arad SA.

Comparando o SFT em relação ao Arad T (Tabela 2) observa-se que a fonte solúvel apenas foi superior $(\mathrm{p}<0,05)$ em MSPA na dose de $224 \mathrm{mg} \mathrm{dm}^{-3}$ e para os teores de $\mathrm{P}$ nas folhas na dose de $560 \mathrm{mg} \mathrm{dm}^{-3}$, não havendo diferença entre as duas fontes, nas demais doses.

$\mathrm{O}$ efeito residual de $\mathrm{P}$ aplicado na soja propiciou teores de P na folha de milho (Tabela 2), dentro da faixa 1,9 a 3,5 $\mathrm{g} \mathrm{kg}^{-1}$, considerada adequada segundo Büll (1993), com exceção da dose $56 \mathrm{mg} \mathrm{dm}^{-3}$ de $\mathrm{P}$ fornecida com SFT e na ausência da aplicação de P. Observa-se também o aumento numérico dos teores conforme o aumento das doses. Em estudo com fontes (FNA, Gafsa, Marrocos e SFT) e doses de P na cultura do milho, em um Latossolo Vermelho Amarelo de textura média, Korndorfer et al. (1999), constataram a existência de correlação positiva entre a produtividade e os teores de $\mathrm{P}$ nas folhas $\left(\mathrm{R}^{2}=0,69 * *\right)$, sugerindo que a análise foliar, nesse caso, pode ser um bom indicativo do seu potencial produtivo.

Para a MSPA e teor de P na folha, o modelo raiz quadrada apresentou o melhor ajuste para FNA. Para o SFT foram, respectivamente, os modelos quadrático e linear que melhor se ajustaram (Figura 3). O teor de $\mathrm{P}$ na folha apresentou uma ligeira tendência de estabilização a partir da dose $56 \mathrm{mg}$ $\mathrm{dm}^{-3}$ de $\mathrm{P}$ na fonte FNA, indicando uma semelhança na disponibilidade do P residual para a planta nessas doses; já com a fonte SFT não se observou a mesma tendência. 


\section{c) Índice de eficiência agronômica (Soja e Milho)}

O Arad SA apresentou maior IEA em comparação ao Arad $\mathrm{T}$ em todas as doses de $\mathrm{P}$ aplicadas no primeiro cultivo (soja), tomando-se como referência a fonte SFT (100\%). O mesmo ocorreu no segundo cultivo (milho), com exceção na dose de $224 \mathrm{mg} \mathrm{dm}^{-3}$ (Tabela 3).

Na média do IEA, o Arad SA superou o Arad T no primeiro cultivo (Tabela 3 ), contudo os dois foram inferiores ao SFT, podendo ser explicado pela menor solubilidade e consequente disponibilidade do FNA, conforme Korndorfer et al. (1999). No segundo cultivo, houve um aumento do IEA em relação ao primeiro e, o Arad SA foi em média 23,9\% superior ao SFT (Tabela 3). $\mathrm{O}$ aumento da eficiência do fosfato de rocha reativo, com o passar do tempo, foi relatado por Braga et al. (1991) e Moreira (1997). Segundo Moreira et al. (2002), o efeito residual dos fosfatos naturais reativos tende a equipararse ao das fontes fosfatadas mais solúveis, o que pode ser atribuído ao esgotamento natural destas fontes, além da acidificação do solo favorecendo a solubilização dos fosfatos naturais.

Tabela 2 - Valores médios de produção de massa seca da parte aérea e teores de P na folha do milho para doses e fontes de P.

\begin{tabular}{|c|c|c|c|c|c|c|}
\hline \multirow[t]{2}{*}{ Fontes } & \multicolumn{6}{|c|}{ Doses de Fósforo $\left(\mathrm{mg} \mathrm{dm}^{-3}\right)$} \\
\hline & 0 & 56 & 112 & 224 & 336 & 560 \\
\hline \multicolumn{7}{|c|}{ - } \\
\hline Arad T & 3,65 a & $19,34 \mathrm{ab}$ & $20,75 \mathrm{~b}$ & $26,35 \mathrm{~b}$ & $29,45 \mathrm{a}$ & $30,25 \mathrm{a}$ \\
\hline Arad SA & $3,90 \mathrm{a}$ & $27,20 \mathrm{a}$ & $30,30 \mathrm{a}$ & $25,35 \mathrm{~b}$ & $30,00 \mathrm{a}$ & $34,63 \mathrm{a}$ \\
\hline SFT & $3,40 \mathrm{a}$ & $14,38 \mathrm{~b}$ & $23,27 \mathrm{ab}$ & $36,53 \mathrm{a}$ & $33,48 \mathrm{a}$ & $31,90 \mathrm{a}$ \\
\hline & \multicolumn{6}{|c|}{---Teores de P na folha $\left(\mathrm{g} \mathrm{kg}^{-1}\right)$} \\
\hline Arad T & $1,18 \mathrm{a}$ & $1,95 \mathrm{a}$ & $2,31 \mathrm{a}$ & $2,34 \mathrm{a}$ & $2,51 \mathrm{a}$ & $2,35 \mathrm{~b}$ \\
\hline Arad SA & $1,22 \mathrm{a}$ & $2,26 \mathrm{a}$ & $2,41 \mathrm{a}$ & $2,44 \mathrm{a}$ & $2,44 \mathrm{a}$ & $2,37 \mathrm{~b}$ \\
\hline SFT & $1,30 \mathrm{a}$ & $1,76 \mathrm{a}$ & $1,99 \mathrm{a}$ & $2,55 \mathrm{a}$ & $2,93 \mathrm{a}$ & $4,23 \mathrm{a}$ \\
\hline
\end{tabular}

Médias seguidas da mesma letra na coluna não diferem pelo teste de Tukey a 5\% de probabilidade.
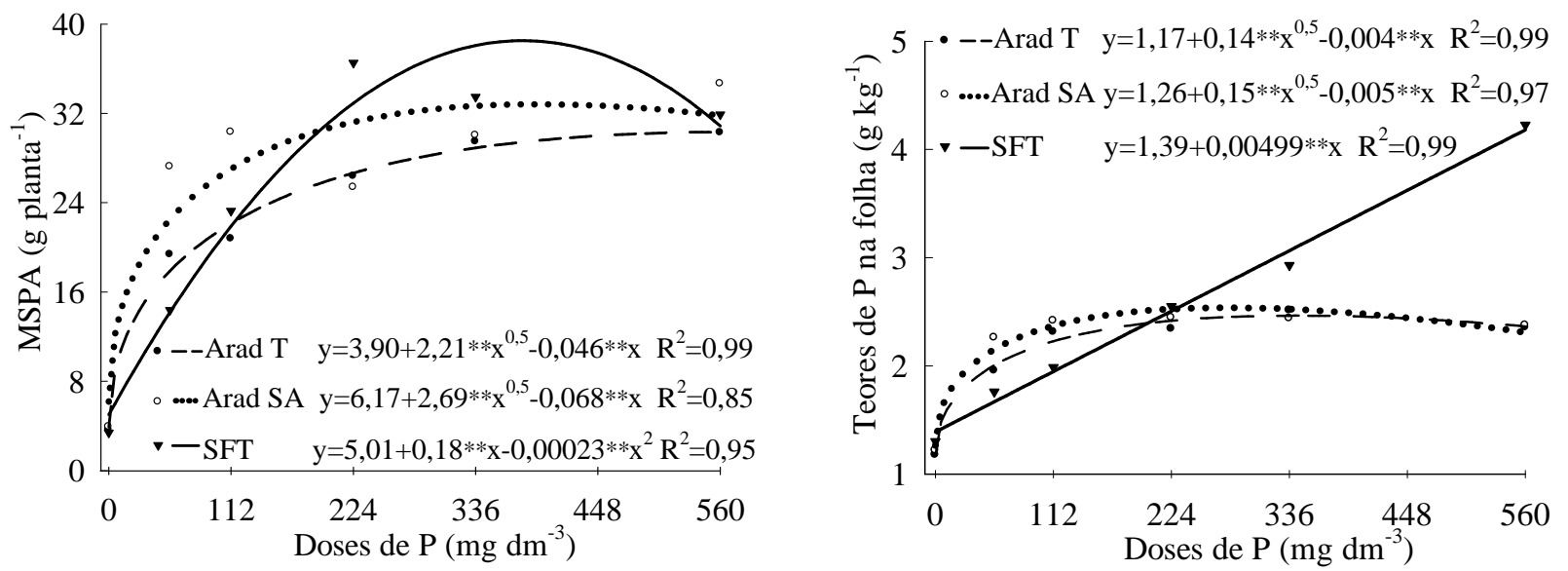

Figura 3 - Produção de massa seca da parte aérea e teores de P na folha de milho em função das doses de P de três fontes utilizadas. $* *$ significativo a $1 \%$ de probabilidade pelo teste $\mathrm{t}$. 
Tabela 3 - Índice de eficiência agronômica em cinco doses de P na cultura da soja e do milho em razão do fosfato natural de Arad.

\begin{tabular}{|c|c|c|c|c|c|c|}
\hline \multirow{2}{*}{ Fontes de $\mathrm{P}$} & \multicolumn{5}{|c|}{ Doses de $\mathrm{P}\left(\mathrm{mg} \mathrm{dm}^{-3}\right)$} & \multirow[b]{2}{*}{ Média* } \\
\hline & 56 & 112 & 224 & 336 & 560 & \\
\hline \multicolumn{7}{|c|}{--10 } \\
\hline Arad T & 57,9 & 55,2 & 53,8 & 56,8 & 48,0 & 54,3 \\
\hline Arad SA & 98,9 & 82,8 & 57,3 & 77,8 & 68,2 & 77,0 \\
\hline & & ----IEA & milho & & & \\
\hline Arad T & 146,2 & 87,2 & 69,0 & 86,5 & 94,2 & 96,6 \\
\hline Arad SA & 219,5 & 135,8 & 66,0 & 88,3 & 109,7 & 123,9 \\
\hline
\end{tabular}

${ }^{1} \mathrm{e}^{2}$, com base na PG e MSPA, respectivamente.

* média dos IEA das cinco doses de P.

\section{CONCLUSÕES}

As culturas responderam à adubação fosfatada independentemente da fonte.

No primeiro cultivo (soja), o SFT apresentou melhor desempenho e IEA para a PG quando comparado ao FNA.

Para o milho, como cultura em sucessão a soja, o FNA tendeu a equiparar-se ao SFT nos atributos avaliados.

$\mathrm{Na}$ sucessão soja-milho o IEA do Arad SA foi superior ao do Arad T.

\section{REFERÊNCIAS BIBLIOGRÁFICAS}

ALVAREZ, V.V.H.; NOVAIS, R.F.; DIAS, L.E.; OLIVEIRA, J.A. Determinação e uso do fósforo remanescente. Boletim Informativo Sociedade Brasileira de Ciência do Solo, Viçosa, v.25, n.1, p.27-32, 2000.

BARNES, J.S.; KAMPRATH, E.J. Availability of North Carolina rock phosphate applied to soils. Raleigh: North Carolina State University, 1975. 23p.

(Agricultural Experiment Station. Technical bulletin, 229).

BRAGA, G. Eficiência de fosfatos com solubilidade variável em água em solos com capacidade de fixação de fósforo induzida. 2006. 82p. Dissertação (Mestrado em Agronomia)-Escola Superior de Agricultura Luiz de Queiroz, Piracicaba, 2006.

BRAGA, J.M.; DEFELIPO, B.V. Determinação espectrofotométrica de fósforo em extratos de solos e plantas. Revista Ceres, Viçosa, v.21, n.113, p.73-85, jan./ fev. 1974
BRAGA, N.R.; MASCARENHAS, H.A.A.; BULISANI, E.A.; RAIJ, B. van; FEITOSA, C.T.; HIROCE, R. Eficiência agronômica de nove fosfatos em quatro cultivos consecutivos de soja. Revista Brasileira de Ciência do Solo, Viçosa, v.15, n.3, p.315-319, 1991.

BÜLL, L.T. Nutrição mineral do milho. In: BÜLL, L.T.; CANTARELLA, H. (Eds.). Cultura do milho: fatores que afetam a produtividade. Piracicaba: Associação Brasileira para Pesquisa da Potassa e do Fosfato, 1993. p.63-145.

GOEDERT, W.J.; LOPES, A.S. Eficiência agronômica de fertilizantes fosfatados para culturas anuais, perenes, pastagens e reflorestamento. In: SEMINÁRIO SOBRE RECUPERAÇÃO DE FÓSFORO, 1987, São Paulo, SP. Anais... São Paulo: IBRAFOS, 1987. p.24-49.

GOMES, A. da S.; SCIVITTARO, W.B.; FERREIRA, L.H.G.; BENDER, R.R. Uso de fosfato natural reativo em arroz irrigado cultivado no sistema convencional. In: CONGRESSO BRASILEIRO DE CIÊNCIA DO SOLO, 30. 2005, Recife, PR. Anais... Recife: SBCS, 2005. CD-ROM.

HARGER, N.; BRITO, O.R.; RALISCHI, R.; ORTIZ, F.R.; WATANABE, T.S. Avaliação de fontes e doses de fósforo no crescimento inicial do milho. Semina:

Ciências Agrárias, Londrina, v.28, n.1, p.39-44, jan./mar. 2007.

HOROWITZ, N.; MEURER, E.J. Eficiência agronômica de fosfatos naturais. In: SIMPÓSIO SOBRE FÓSFORO NA AGRICULTURA BRASILEIRA, 2003, Piracicaba, SP. Anais... Piracicaba: POTAFOS/ANDA, 2003. CD-ROM. 
KORNDORFER, G.H.; CABEZAS, W.A.L.; HOROWITZ, N. Eficiência agronômica de fosfatos naturais reativos na cultura do milho. Scientia Agrícola, Piracicaba, v.56, n.2, p.1-9, 1999.

MALAVOLTA, E.; VITTI, G.C.; OLIVEIRA, S.A. de. Avaliação do estado nutricional das plantas: princípios e aplicações. Piracicaba: POTAFOS, 1997. 289p.

\section{MOREIRA, A. Efeito de fontes e doses de fósforo na} alfafa (Medicago sativa L.) e centrosema (Centrosema pubens Benth.) e avaliação de extratores. 1997.

Dissertação (Mestrado em Agronomia)-Escola Superior de Agricultura Luiz de Queiroz, Piracicaba, 1997.

MOREIRA, A.; MALAVOLTA, E.; MORAES, L.A.C. Eficiência de fontes e doses de fósforo na alfafa e centrosema cultivadas em Latossolo Amarelo. Pesquisa Agropecuária Brasileira, Brasília, v.37, n.10, p.14591466, out. 2002.

NOVAIS, R.F.; NEVES, J.C.L.; BARROS, N.F. Ensaio em ambiente controlado. In: OLIVEIRA, A.J. de; GARRIDO, W.E.; ARAÚJO, J.D. de; LOURENÇO, S. (Coord.).

Métodos de pesquisa em fertilidade do solo. Brasília, DF: Embrapa-SEA, 1991. p.189-253. (Embrapa-SEA.

Documentos, 3).

NOVAIS, R.F.; SMYTH, T.J. Fósforo em solo e planta em condições tropicais. Viçosa, MG: UFV, 1999. 399p.
RAIJ, B. van. Fósforo no solo e interação com outros elementos. In: YAMADA, T.; ABDALLA, S.R.S. Fósforo na agricultura brasileira. Piracicaba: POTAFOS, 2004. p.106-114.

RAIJ, B. van; QUAGGIO, J.A.; SILVA, N.M. Extraction of phosphorus, potassium, calcium and magnesium from soils by an ion-exchange resin procedure.

Communicátions in Soil Science and Plant Analysis, New York, v.17, n.5, p.547-566, 1986.

RESENDE,A.V.de; FURTINI NETO,A.E.; ALVES, V.M.C.; MUNIZ, J.A.; CURI, N.; FAQUIN, V.; KIMPARA, D.I.; SANTOS, J.Z.L.; CARNEIRO, L.F. Fontes e modos de aplicação de fósforo para o milho em solo cultivado da região do cerrado. Revista Brasileira de Ciência do Solo, Viçosa, v.30, n.3, p.453-466, 2006.

SANTOS, J.Z.L.; BARCELOS, L.V.; CANTAO, F.O.; LIMA, R.K.; JUNIOR, P.P.; COSTA, S.E.V.G.A.; RESENDE, A.V.; FURTINI NETO, A.E.; ANDRADE, M.J.B. Resposta de diferentes culturas ao superfosfato triplo e ao fosfato reativo de arad em latossolo vermelho amarelo. In: CONGRESSOBRASILEIRODE CIÊNCIA DO SOLO, 30, 2005, Recife, PR. Anais... Recife: SBCS, 2005. CD-ROM.

SILVA, D.J.; ALVARENGA, R.C.; ALVAREZ, V.H.; SOARES, P.C. Localização de fósforo e de cálcio no solo e seus efeitos sobre o desenvolvimento inicial do milho. Revista Brasileira de Ciência do Solo, Campinas, v.17, p.203-209, 1999. 